\title{
Changes in foot pain, structure and function following bariatric surgery
}

Tom P. Walsh ${ }^{1,2^{*}}$ (D), Tiffany K. Gill ${ }^{3}$, Angela M. Evans ${ }^{4}$, Alison Yaxley ${ }^{5}$, Jacob A. Chisholm ${ }^{6}$, Lilian Kow ${ }^{6}$, John B. Arnold ${ }^{7}$ and E. Michael Shanahan ${ }^{1,8}$

\begin{abstract}
Background: Bariatric surgery candidates have a high prevalence of foot pain, depression and elevated plantar pressures. There is, however, limited research into how these factors interact pre- and post-surgery. The aims of this study were therefore to investigate the mechanical and non-mechanical factors associated with foot pain severity before, and the change after, surgery.
\end{abstract}

Methods: Bariatric surgery candidates underwent baseline and six-month follow-up measures. Foot pain was measured with the Manchester-Oxford Foot Questionnaire. Mechanical measures included body mass index (BMI), dynamic plantar pressures, radiographic foot posture, and hindfoot range of motion. Depressive symptoms, the non-mechanical measure, were assessed by questionnaire. Multivariable linear regression was used to determine which variables were associated with foot pain at baseline and at follow-up. Multilevel repeated models assessed the associations between foot pain and plantar pressure, adjusting for the interaction between group and follow-up time.

Results: Forty-five participants (84\% female), with mean (SD) age of 45.7 (9.4) years were recruited. Twenty-nine participants had bariatric surgery and 16 participants remained on the waiting list (controls). Following bariatric surgery, foot pain reduced significantly by -35.7 points ( $95 \% \mathrm{Cl}-42.2$ to -28.8 ), while depressive symptoms and whole foot peak pressures had a significant mean change of -5.9 points ( $95 \% \mathrm{Cl}-10.3$ to -1.5$)$ and $-36 \mathrm{kPa}(95 \% \mathrm{Cl}-50$ to -22$)$, respectively. In multivariable analysis, depressive symptoms were associated with foot pain at baseline $\beta=0.7(95 \% \mathrm{Cl}$ 0.2 to 1.2) after controlling for age, gender, BMI, foot posture and plantar pressure. Depressive symptoms were also associated with foot pain at follow-up in those undergoing bariatric surgery, $\beta=1.2$ ( $95 \% \mathrm{Cl} 0.8$ to 1.7). Foot posture and hindfoot range of motion did not change following surgery and a change in plantar pressures was not associated with a change in foot pain.

Conclusions: Foot pain severity in bariatric surgery candidates was associated with depressive symptoms at baseline. Reduced foot pain following bariatric surgery was associated with an improvement in depressive symptoms, without a significant change in foot posture or foot function. Foot pain severity in bariatric candidates may be mediated by nonmechanical or non-local factors before and following surgery.

Keywords: Foot, Pain, Obesity, Bariatric surgery

\footnotetext{
* Correspondence: wals0169@flinders.edu.au

${ }^{1}$ College of Medicine and Public Health, Flinders University, Bedford Park,

South Australia 5042, Australia

Department of Orthopaedics and Trauma, The Queen Elizabeth Hospital,

Woodville South, South Australia 5011, Australia

Full list of author information is available at the end of the article
}

(c) The Author(s). 2018 Open Access This article is distributed under the terms of the Creative Commons Attribution 4.0 International License (http://creativecommons.org/licenses/by/4.0/), which permits unrestricted use, distribution, and reproduction in any medium, provided you give appropriate credit to the original author(s) and the source, provide a link to the Creative Commons license, and indicate if changes were made. The Creative Commons Public Domain Dedication waiver (http://creativecommons.org/publicdomain/zero/1.0/) applies to the data made available in this article, unless otherwise stated. 


\section{Background}

Foot pain is a common complaint, affecting almost one in four adults aged over 45 years [1]. Obesity is a risk factor for the development of foot pain [2], and an elevated body mass index (BMI) is strongly associated with both chronic plantar heel pain and non-specific foot pain [3]. Moreover, the feet of people with obesity are structurally and functionally different to their non-obese counterparts, manifesting as thicker, wider and larger, along with flatter-foot postures, reduced joint range of motion and increased peak plantar pressures $[4,5]$. It is therefore conceivable that foot pain in people with obesity is related to these mechanical adaptations, particularly the flattening of the foot arches and the increase in plantar pressures.

Studies have found that people with obesity display increases in plantar pressures that are not uniform, with the areas of highest pressure being the midfoot and forefoot, when compared to non-obese people [5-7]. Given that obesity is strongly associated with plantar heel pain $[8,9]$, increased plantar pressure elsewhere is discordant if pain was strongly related to excessive pressure. Paradoxically, people with chronic plantar heel pain display reduced loading under the heel when compared to controls [10]. Indeed, pain may persist even when gait patterns change to offload a painful region of the foot. Thus, chronic foot pain in people with obesity may be more than mechanical overload, involving a complex interplay between mechanical, metabolic and psychological factors.

Musculoskeletal pain has a bidirectional relationship with both obesity [11] and depression [12], while depression and obesity also amplify each other [13]. These relationships, however, are not limited to weight-bearing joints with a known association between elevated BMI and symptomatic hand osteoarthritis [14], suggesting that metabolic mechanisms, including systemic inflammation [15], may underpin the relationship between obesity and joint pain [16]. Whilst these relationships exist in the general population, it is particularly pertinent in bariatric surgery candidates, who are over-represented amongst those complaining of musculoskeletal pain [17]; with foot and ankle pain prevalence cited as $34-50 \%[18,19]$. There is evidence that spatiotemporal gait patterns, such as increased limb swing and decreased double-limb support time [20] improve following bariatric surgery, but currently only limited investigations regarding associations between weight loss in a bariatric cohort and changes in foot pain, foot function and foot posture. In order to effectively develop and understand treatment methods, it is important to determine whether weight loss has a direct influence on foot structure and function that could be linked with pain, given the high prevalence of obesity across the community [21].
Despite a high prevalence of foot pain, depression and elevated plantar pressures, there is little evidence that mechanical and non-mechanical factors relate to foot pain before and after bariatric surgery. Therefore, the aims of this study were to investigate changes in foot pain, posture and function after bariatric surgery compared to a group remaining on the waiting-list, acting as controls, and to determine the factors related to changes in foot pain post-surgery.

\section{Methods \\ Participants}

This study recruited a convenience sample of people with foot pain from bariatric surgery waiting lists at two tertiary hospitals in Adelaide, South Australia between January 2015 and June 2017. All patients on the lists were invited to participate in this study. Participants were recruited either immediately before surgery (treatment group) or when they were added to the waiting list (control group). All participants underwent baseline measures and were reassessed at six-month follow-up. Baseline measures for participants in the treatment group were recorded 2-3 weeks prior to surgery, designed to reduce the impact of non-surgical weight loss that occurs with meal replacements prior to surgery. Bariatric surgery procedures (sleeve gastrectomy, laparoscopic adjustable gastric band or Roux-en-Y gastric bypass) were based on the clinical requirements of each patient, and not directed by this study. The study received ethical approval before commencement by the Southern Adelaide Clinical Human Research Ethics Committee (Project ID 211.14).

\section{Inclusion and exclusion criteria}

People aged $\geq 18$ years were recruited if they reported current foot pain of $\geq 30 \mathrm{~mm}$ on a visual analogue scale [22], indicating moderate pain (at least), which had to have been present for $\geq 3$ months. Participants were excluded if: pregnant, history of previous bariatric or foot surgery, systemic inflammatory disease, loss of peripheral sensation in the feet, known infectious disease, cancer, non-ambulatory.

\section{Demographic and anthropometric data}

Self-reported age and gender were recorded at baseline. Body weight and height were measured to the nearest $0.1 \mathrm{~kg}$ and $0.1 \mathrm{~cm}$, respectively using an electronic stadiometer (with shoes, socks, and bulky clothing removed) (Seca 284, Germany). From these data, BMI (weight $(\mathrm{kg}) /$ height $\left(\mathrm{m}^{2}\right)$ ) was calculated [23].

\section{Foot pain}

Foot pain and disability were assessed using the Manchester-Oxford Foot and Ankle Questionnaire 
(MOXFQ). The MOXFQ is a reliable and valid 16-item questionnaire that comprises three separate underlying dimensions: walking/standing problems (seven items), foot pain (five items), and social interaction (four items). Item responses are each scored from 0 to 4 , with 4 representing the most severe state [24]. The MOXFQ-index is a summary score that incorporates all three domains and was used for this study as it investigates overall foot pain and disability and is graded on a 0 to 100 scale, with 100 being the most severe state.

\section{Depressive symptoms}

The Center for Epidemiologic Studies Depression scale (CES-D) consists of 20-items that assess depressive symptoms [25]. All items are graded via a four-point (0 to 3) Likert scale, giving a possible range of 0-60. The sum score was used as a continuous variable to assess depressive symptoms at baseline and follow-up.

\section{Plantar pressure}

Dynamic plantar pressure data were collected with the MatScan $^{\circ}$ (Tekscan, USA) platform system at baseline and follow-up. The platform is a $5 \mathrm{~mm}$-thick floor mat $(432 \times 368 \mathrm{~mm})$ incorporating 2288 resistive sensors (sensor size $=0.70 \mathrm{~cm}^{2}, 1.4$ sensors $/ \mathrm{cm}^{2}$ ) with data sampled at a rate of $40 \mathrm{~Hz}$. Analyses conducted using the MatScan ${ }^{\circ}$ platform have been previously shown to have good accuracy [26] and moderate to good inter-session reliability in adults, for total peak pressure and maximum force ICC (95\% CI) of $0.58(0.28$ to 0.75$)$ and 0.92 (0.84 to 0.96), respectively [27]. The MatScan ${ }^{\circ}$ platform was positioned in a level walkway. Following individual step calibration, which involved entering the participant's body weight followed by a period of standing on the MatScan ${ }^{\circ}$ platform, balancing on one foot. The participants were then asked to walk barefoot with their usual gait pattern across the MatScan ${ }^{\circ}$ platform. Data were collected using a midgait protocol, whereby participants were instructed to take two steps, striking the platform on their third step, before continuing to walk for a further three steps. The midgait protocol has been found to have moderate to excellent reliability, for total peak pressure and maximum force ICC of 0.52 to 0.97 and 0.36 to 0.73 , respectively [28]. Data were collected from three complete, valid trials of the right foot. A valid trial was determined when participants' gait pattern was not perturbed and when no 'targeting' of the plantar pressure platform occurred. Individual "masks" were manually constructed to determine plantar pressures for the whole foot and also five regions of the foot; heel, midfoot, forefoot, hallux and lesser toes, using the Research Foot software (version 6.51). Measures of regional contact area $\left(\mathrm{cm}^{2}\right)$, maximum force $(\mathrm{kgf})$, peak plantar pressure $(\mathrm{kPa})$ and contact time $(\mathrm{ms})$ were calculated for all trials to obtain a mean value. The right foot was chosen to ensure that the assumption of independence of data was met [29] and additional measures such as mean pressure or pressure-time integral were not collected given the interdependence between these measures and peak pressure [30,31]. Contact time was used as a proxy for walking speed [32].

\section{Radiographic measures}

Weight-bearing dorsoplantar and lateral radiographs were taken at baseline and follow-up using a standardised technique on a digital radiograph unit (Ysio, Siemens Healthcare, Germany). Dorsoplantar views were taken with the participant standing above the image receptor on both feet, the central beam was angled at 15 degrees towards the calcaneus and the centering point was aimed at the base of the third metatarsal. Lateral radiographs were taken with the participant standing on a platform, the image receptor was positioned on the medial aspect of the foot and the centering point was at the base of the metatarsals from a lateral to medial direction.

Foot posture was assessed using four radiographic angles described by Murley et al. [33]. The calcaneal inclination angle is the angle between the inferior aspect of the calcaneus and the supporting surface, while the calcaneal-first metatarsal angle is the angle on the dorsum of the foot taken between the inferior calcaneal angle and a line parallel to the midshaft of the first metatarsal. Both of these angles were measured from the lateral view. The calcaneal-first metatarsal angle was used as a measure of foot posture in the regression analyses, having been shown to strongly correlate with clinical measures [33].

Two further angles were taken from the dorso-plantar radiograph: the talo-navicular and talo-second metatarsal angle. The anteromedial and anterolateral extremes of the talar head and the bisection of the proximal articular surface of the navicular formed the talo-navicular angle. The talo-second metatarsal angle is formed between the bisection of the shaft of the second metatarsal and the line perpendicular to the anteromedial and anterolateral extremes of the head of the talus.

\section{Hindfoot range of motion}

Ankle joint dorsiflexion was measured using the technique described by Munteanu et al. [34], which has very good intra- and inter-rater reliability (ICC (95\% CI) 0.88 (0.75-0.94) and $0.92(0.86-0.96))$ when taken in a weight-bearing position with the knee in full extension. A digital protractor (Gain Express, USA) was placed on the anterior aspect of the tibia and the angle between the ground and the leg was recorded. The measure was repeated in duplicate and a mean was obtained. 
Frontal plane range of motion of the hindfoot (ankle and subtalar joints) was measured using the technique described by Menadue et al. [35]. Participants are seated in an upright position with the foot positioned overhanging the examination table. The foot was moved from maximal abduction to maximal adduction with the total range of motion recorded with a goniometer (Physio-Med, AUS), this measure was repeated in duplicate and a mean was obtained.

\section{Data analysis}

Descriptive statistics (frequencies and means) were obtained. All data distributions were checked for normality via the inspection of histograms and the Shapiro-Wilks test prior to inferential statistical analysis. Differences between the treatment and control groups at baseline were assessed using chi-squared tests for categorical data and t-tests or Mann-Whitney $U$ tests for continuous data that was normally or non-normally distributed, respectively. Multivariable linear regression was used to analyse the association between foot pain severity and mechanical (foot posture, plantar pressure, BMI) and non-mechanical (depressive symptoms) variables, along with age and gender at baseline and follow-up. Within group differences in contact area, force and peak plantar pressure between baseline and follow-up were analysed with either the paired-samples t-test or the Wilcoxon signed-rank test. As repeated measures were taken over six-months, a multilevel repeated model using the xtmixed command in STATA was used to assess the associations between MOXFQ-index and peak plantar pressure and other covariates (ankle joint range of motion [36], contact time [37], age and gender [38]) for both groups over six-months while adjusting for the interaction between group and follow-up time. This type of regression model allows for the correlations of observations within subjects. In all analyses, $p$ values (two-sided) less than 0.05 were deemed to be statistically significant. All data analyses were performed with SPSS V25 (IBM SPSS Statistics, Armonk, NY, USA) and STATA V15 (StataCorp College Station, TX, USA).

\section{Results}

\section{Participant characteristics}

This study recruited 45 participants (38 women), with a mean (standard deviation) (SD) age of 45.7 (9.4) years. Twenty-nine participants had bariatric surgery, undergoing a Roux-en-Y gastric bypass $(n=13)$, sleeve gastrectomy $(n=11)$, or laparoscopic adjustable gastric band $(n=5)$. Sixteen participants remained on the waiting-list and were used as controls. There were no significant differences in the characteristics between those undergoing bariatric surgery and those in the control group (Table 1). All participants underwent baseline measures, one participant who underwent bariatric surgery was lost to follow-up as they were uncontactable. Two additional participants from the treatment group were unavailable for follow-up plantar pressure data collection and four participants from the control group were unavailable for follow-up plantar pressure and foot posture data collection.

\section{Baseline and follow-up foot pain}

In multivariable regression analysis, only depressive symptoms were significantly associated with foot pain severity measured by MOXFQ at baseline ( $\beta=0.7,95 \%$ CI 0.2 to $1.2, p=0.008$ ). Age, gender, BMI, foot posture and whole-foot plantar pressure were included in the model, but these were not significantly related to foot pain severity, although age and BMI were trending towards statistical significance (Table 2). Multivariable regression analysis of the treatment group at follow-up found foot pain severity was also associated with depressive symptoms $(\beta=1.2,95 \%$ CI 0.8 to $1.7, p<0.001)$, while age, gender, foot posture and whole foot plantar pressure were not significantly associated with foot pain. There were no significant associations between foot pain severity and any of the listed variables in the control group (Table 3). The treatment group had a significant reduction in foot pain of 35.7 points (95\% CI -42.2 to 28.8, $p<0.001$ ), while the control group had a small non-significant reduction of 4.0 points ( $95 \% \mathrm{CI}-15.2$ to $7.1, p=0.454$ ) (Table 4). Nine people (one-third) in the treatment group had complete resolution of their foot pain at 6-months follow-up.

\section{Change in mechanical and non-mechanical variables following bariatric surgery}

The 29 participants who underwent bariatric surgery had a mean reduction in weight of $24.3 \mathrm{~kg}$ (95\% CI -27.5 to - 21.1, $p<0.001$ ), representing a mean per cent change in body weight of $19.9 \%$ (range 0.9 to $31.8 \%$ ). The 16 participants who did not have bariatric surgery had a mean weight gain of $1.2 \mathrm{~kg}$ ( $95 \% \mathrm{CI}-2.5$ to $4.9, p=0.877)$. In the treatment group, there were significant reductions in force and peak pressure in multiple regions, although the midfoot was the only site to exhibit a statistically significant mean reduction in contact area of $2.1 \mathrm{~cm}^{2}$ (95\% CI -3.9 to $-0.3, p=0.022$ ). Representative peak plantar pressures of participants before and after bariatric surgery are depicted in Fig. 1. In the control group, the only region to demonstrate a statistically significant change in plantar pressure was the whole foot variable, which increased by a mean $13 \mathrm{kPa}(95 \%$ CI 0 to 25 , $p=0.046)$. Depressive symptoms reduced in both groups, although only the treatment group had a significant mean reduction of 5.9 points ( $95 \% \mathrm{CI}-10.3$ to $-1.5, p=0.007$ ). There was no significant change in the ankle joint range of motion or foot posture in either the 
Table 1 Baseline characteristics of the treatment and control groups ${ }^{\wedge a}$

\begin{tabular}{|c|c|c|c|}
\hline & Treatment group $(n=27)$ & $\begin{array}{l}\text { Control group } \\
(n=16)\end{array}$ & $p$ value \\
\hline Age, years & $45.1(9.0)$ & $45.3(10.4)$ & 0.958 \\
\hline Gender, women, $n(\%)^{\mathrm{b}}$ & $25(86.2)$ & $13(81.3)$ & 0.661 \\
\hline Height, m & $1.7(0.1)$ & $1.7(0.1)$ & 0.906 \\
\hline Weight, kg & $123.9(19.4)$ & $132.4(15.5)$ & 0.140 \\
\hline Body mass index, $\mathrm{kg} / \mathrm{m}^{2}$ & $44.8(7.0)$ & $47.9(5.2)$ & 0.120 \\
\hline MOXFQ-index, points & $49.7(18.5)$ & $61.0(23.0)$ & 0.081 \\
\hline Sum CES-D score & $16.9(11.6)$ & $22.3(12.0)$ & 0.151 \\
\hline \multicolumn{4}{|l|}{ Plantar pressures } \\
\hline \multicolumn{4}{|l|}{ Contact area $\left(\mathrm{cm}^{2}\right)$} \\
\hline Whole foot & $181.2(26.7)$ & $185.2(23.2)$ & 0.625 \\
\hline Forefoot ${ }^{c}$ & $62.3(9.3)$ & $63.5(8.6)$ & 0.910 \\
\hline Hallux ${ }^{c}$ & $34.0(6.9)$ & $35.9(13.3)$ & 0.940 \\
\hline Heel & $54.0(8.6)$ & $55.1(5.0)$ & 0.659 \\
\hline Lesser toes & $31.8(5.6)$ & $31.7(6.9)$ & 0.952 \\
\hline Midfoot & $45.8(10.6)$ & $46.9(6.1)$ & 0.658 \\
\hline \multicolumn{4}{|l|}{ Force (kgf) } \\
\hline Whole foot & $149.5(31.5)$ & $155.7(17.5)$ & 0.479 \\
\hline Forefoot & $97.3(20.6)$ & $99.8(14.4)$ & 0.669 \\
\hline Hallux $x^{c}$ & $33.9(7.2)$ & $36.1(13.1)$ & 0.950 \\
\hline Heel & $80.7(19.6)$ & $85.8(10.8)$ & 0.284 \\
\hline Lesser toes & $31.2(7.5)$ & $30.8(9.1)$ & 0.870 \\
\hline Midfoot & $41.4(11.3)$ & $41.6(8.9)$ & 0.953 \\
\hline \multicolumn{4}{|l|}{ Plantar pressure (kPa) } \\
\hline Whole foot ${ }^{c}$ & $386(50)$ & $393(34)$ & 0.920 \\
\hline Forefoot & $366(56)$ & $370(41)$ & 0.785 \\
\hline Hallux & $170(43)$ & $186(74)$ & 0.437 \\
\hline Heel & $354(61)$ & $365(56)$ & 0.561 \\
\hline Lesser toes & $54(20)$ & $60(22)$ & 0.375 \\
\hline Midfoot & $181(77)$ & $197(55)$ & 0.472 \\
\hline Contact time (seconds) & $0.9(0.1)$ & $0.9(0.1)$ & 0.745 \\
\hline \multicolumn{4}{|l|}{ Hindfoot ROM (degrees) } \\
\hline Frontal plane $e^{c}$ & $40.9(6.3)$ & $38.3(4.7)$ & 0.094 \\
\hline Dorsiflexion & $61.2(5.0)$ & $62.4(6.4)$ & 0.492 \\
\hline \multicolumn{4}{|l|}{ Foot posture (degrees) } \\
\hline Talo-second metatarsal angle & $12.0(8.4)$ & $8.8(10.1)$ & 0.265 \\
\hline Talo-navicular angle & $15.3(6.9)$ & $11.4(7.6)$ & 0.092 \\
\hline Calcaneal inclination angle ${ }^{c}$ & $20.6(4.9)$ & $22.1(3.6)$ & 0.445 \\
\hline Calcaneal-first metatarsal angle & $133.1(6.3)$ & $131.6(6.0)$ & 0.420 \\
\hline
\end{tabular}

SD standard deviation, $m$ metres, $\mathrm{kg}$ kilograms, $\mathrm{m}^{2}$ metres squared, $\mathrm{cm}^{2}$ centimetres squared, CES-D Center for Epidemiological Studies-Depression scale, MOXFQ Manchester-Oxford Foot Questionnaire, $\mathrm{kPa}$ kilopascal, $R O M$ range of motion

${ }^{a} p$ calculated for differences between the treatment and control groups analysed with the independent samples t-test

${ }^{\mathrm{b}} p$ calculated for differences between the treatment and control groups analysed with the chi-squared test

${ }^{c} p$ calculated for differences between the treatment and control groups analysed with the Mann-Whitney $U$ test

values are mean (SD) unless otherwise stated 
Table 2 Multivariable relationships with MOXFQ-index at baseline for all participants $(n=43)$

\begin{tabular}{lll}
\hline & $\beta$-coefficients $(95 \% \mathrm{Cl})$ & $p$ value \\
\hline Age & $0.6(-0.1$ to 1.4$)$ & 0.095 \\
Gender (female) & $-0.5(-17.2$ to 16.3$)$ & 0.954 \\
Body mass index & $1.0(-0.0$ to 2.0$)$ & 0.052 \\
Depressive symptoms $^{a}$ & $0.7(0.2$ to 1.2$)$ & 0.008 \\
Foot posture $^{b}$ & $-0.6(-1.5$ to 0.3$)$ & 0.206 \\
Plantar pressure $^{c}$ & $-0.1(-0.2$ to 0.1$)$ & 0.424
\end{tabular}

MOXFQ Manchester-Oxford Foot Questionnaire, $\mathrm{Cl}$ confidence interval

${ }^{a}$ sum Center for Epidemiological Studies-Depression scale score

b calcaneal-first metatarsal angle

c whole foot peak pressure

treatment group or the control group between baseline and follow-up. The crude changes between baseline and follow-up are detailed in Table 4.

\section{Repeated measures analysis for change in MOXFQ-index and plantar pressure}

The change in foot pain severity between baseline and follow-up was not associated with peak pressure when adjusted for other covariates. Both group $(\beta=-11.2,95 \% \mathrm{CI}$ -23.8 to $1.4, p=0.081)$ and follow-up time $(\beta=-7.7,95 \% \mathrm{CI}$ -18.5 to $3.2, p=0.168$ ) variables were associated with a reduction in foot pain, but only the group*time (6-months) interaction was statistically significant $(\beta=-21.1,95 \% \mathrm{CI}$ -40.8 to $-13.5, p<0.001$ ) (Table 5).

\section{Discussion}

This is the first study to comprehensively examine the effect of weight loss following bariatric surgery on foot pain, and to explore the mechanical and non-mechanical factors associated with foot pain severity. Depressive symptoms were associated with foot pain severity at baseline, after accounting for age, gender, BMI, foot posture and plantar pressure. At follow-up, foot pain severity was associated with depressive symptoms in those who had undergone bariatric surgery. The change in plantar pressure, walking speed or ankle joint dorsiflexion was not associated with a change in foot pain following bariatric surgery, but weight loss following bariatric surgery resulted in a significant reduction in foot pain severity at 6-months. Therefore, in this cohort, both baseline foot pain and change in foot pain appear more strongly related to non-mechanical or non-local factors.

Previous studies examining the association between the change in weight and change in plantar pressure have largely focused on the effect of weight gain. The effect of weight gain on plantar pressures has been frequently performed on asymptomatic participants, using weighted backpacks as a proxy for the increase in weight $[8,39]$. This method, while practical, measures the instantaneous effect of a change in weight and does so in asymptomatic feet, and therefore may not accurately reflect how pressures change over time in symptomatic feet. This method is also impractical in assessing weight loss. Investigations analysing the effects of weight loss are limited, although a randomised controlled trial investigated the effects of non-surgical weight loss on plantar pressures, albeit in asymptomatic participants, and found that even a small amount of weight loss can significantly reduce mean peak plantar pressure across multiple regions of the foot [40]. This study found that larger weight loss following bariatric surgery results in widespread reductions in plantar pressures in symptomatic feet, with the largest reduction in plantar pressure found in the midfoot.

Interestingly, the reduction in midfoot pressure in the treatment group occurred without a significant change in radiographic foot posture and may therefore be related to soft tissue changes. A previous cross-sectional study found that people with obesity have increased three-dimensional foot circumference at multiple sites when compared to people with a healthy weight [41], these differences are likely soft tissue related. Moreover, the change in BMI and midfoot pressure is concordant with a previous study investigating weight gain and plantar pressure [42], and suggests that the midfoot may be a region that is the most responsive to a change in

Table 3 Multivariable relationships with MOXFQ-index at follow-up for the treatment group and the control group

\begin{tabular}{|c|c|c|c|c|}
\hline & \multicolumn{2}{|l|}{ Treatment group $(n=26)$} & \multicolumn{2}{|l|}{ Control groups $(n=12)$} \\
\hline & $\overline{\beta \text {-coefficients (95\% Cl) }}$ & $p$ value & $\overline{\beta \text {-coefficients (95\% Cl) }}$ & $p$ value \\
\hline Age & $0.2(-0.3$ to 0.8$)$ & 0.434 & $0.7(-2.2$ to 3.6$)$ & 0.582 \\
\hline Gender (female) & $-1.1(-14.3$ to 12.0$)$ & 0.858 & $19.1(-56.5$ to 94.6$)$ & 0.545 \\
\hline Body mass index & $0.4(-0.3$ to 1.1$)$ & 0.280 & $1.3(-4.8$ to 7.4$)$ & 0.609 \\
\hline Depressive symptoms $^{a}$ & $1.2(0.8$ to 1.7$)$ & $<0.001$ & $1.3(-1.1$ to 3.7$)$ & 0.229 \\
\hline Foot posture ${ }^{b}$ & $-0.2(-0.8$ to 0.4$)$ & 0.515 & $0.3(-5.9$ to 6.5$)$ & 0.915 \\
\hline Plantar pressure ${ }^{c}$ & $0.1(-0.0$ to 0.1$)$ & 0.291 & $-0.0(-1.2$ to 1.2$)$ & 0.959 \\
\hline
\end{tabular}

MOXFQ Manchester-Oxford Foot Questionnaire, $\mathrm{Cl}$ confidence interval

${ }^{a}$ sum Center for Epidemiological Studies-Depression scale score

${ }^{\mathrm{b}}$ calcaneal-first metatarsal angle

cwhole foot peak pressure 
Table 4 Comparison between baseline and six-month follow-up measures of body weight, foot pain, depressive symptoms, plantar pressure, foot posture and ankle joint range of motion for treatment and control groups ${ }^{\text {a }}$

\begin{tabular}{|c|c|c|c|c|c|c|}
\hline & \multicolumn{2}{|c|}{ Treatment group $(n=26)$} & \multirow[b]{2}{*}{$p$ value } & \multicolumn{2}{|c|}{ Control group $(n=12)$} & \multirow[b]{2}{*}{$p$ value } \\
\hline & Mean difference & $95 \% \mathrm{Cl}$ & & Mean difference & $95 \% \mathrm{Cl}$ & \\
\hline Weight, kg & -24.3 & -27.5 to -21.1 & $<0.001$ & 1.2 & -2.5 to 4.9 & $0.877^{b}$ \\
\hline Body mass index, $\mathrm{kg} / \mathrm{m}^{2}$ & -8.8 & -10.0 to -7.6 & $<0.001$ & 0.5 & -0.8 to 1.8 & 0.440 \\
\hline MOXFQ-index, points & -35.7 & -42.7 to -28.8 & $<0.001$ & -4.0 & -15.2 to 7.1 & 0.454 \\
\hline Sum CES-D score & -5.9 & -10.3 to -1.5 & $0.007^{b}$ & -4.6 & -9.6 to 0.3 & $0.061^{b}$ \\
\hline \multicolumn{7}{|l|}{ Contact area $\left(\mathrm{cm}^{2}\right)$} \\
\hline Whole foot & -3.4 & -8.7 to 2.0 & 0.210 & -3.8 & -6.7 to -0.9 & 0.014 \\
\hline Forefoot & -0.1 & -2.1 to 1.9 & $0.427^{b}$ & 0.7 & -0.6 to 2.1 & $0.239^{b}$ \\
\hline Hallux & 1.0 & -0.7 to 2.8 & 0.232 & 1.8 & -3.3 to 6.9 & $0.844^{b}$ \\
\hline Heel & -1.4 & -3.4 to 0.6 & 0.155 & -0.4 & -2.0 to 1.2 & 0.579 \\
\hline Lesser toes & -0.0 & -1.8 to 1.7 & 0.960 & 1.2 & -1.3 to 3.8 & 0.306 \\
\hline Midfoot & -2.1 & -3.9 to -0.3 & 0.022 & 0.0 & -1.5 to 1.6 & 0.946 \\
\hline \multicolumn{7}{|l|}{ Force (kgf) } \\
\hline Whole foot & -30.2 & -36.3 to -24.2 & $<0.001$ & 7.1 & -2.4 to 16.6 & 0.126 \\
\hline Forefoot & -18.7 & -24.4 to -13.0 & $<0.001^{\mathrm{b}}$ & 6.0 & 0.7 to 11.3 & $0.010^{b}$ \\
\hline Hallux & 1.5 & -0.9 to 3.9 & 0.215 & -0.3 & -2.7 to 2.1 & $0.724^{b}$ \\
\hline Heel & -13.9 & -18.2 to -9.5 & $<0.001$ & 1.5 & -3.0 to 6.1 & 0.477 \\
\hline Lesser toes & -0.0 & -1.8 to 1.7 & 0.961 & 0.6 & -1.6 to 2.7 & 0.581 \\
\hline Midfoot & -6.5 & -9.2 to -3.9 & $<0.001$ & 0.1 & -3.3 to 3.5 & 0.930 \\
\hline \multicolumn{7}{|l|}{ Plantar pressure (kPa) } \\
\hline Whole foot & -36 & -50 to -22 & $<0.001$ & 13 & 0 to 25 & 0.046 \\
\hline Forefoot & -40 & -56 to -25 & $<0.001$ & 123 & -3 to 28 & 0.098 \\
\hline Hallux & -16 & -31 to -2 & 0.031 & 3 & -15 to 21 & 0.705 \\
\hline Heel & -45 & -65 to -25 & $<0.001$ & 10 & -10 to 30 & 0.276 \\
\hline Lesser toes & -3 & -9 to 3 & 0.366 & 3 & -9 to 16 & $0.456^{b}$ \\
\hline Midfoot & -45 & -63 to -26 & $<0.001$ & 3 & -14 to 20 & 0.709 \\
\hline Contact time (seconds) & -0.0 & -0.0 to 0.0 & 0.617 & 0.0 & -0.0 to 0.0 & 0.553 \\
\hline \multicolumn{7}{|l|}{ Hindfoot ROM (degrees) } \\
\hline Frontal plane & -1.4 & -4.2 to 1.4 & $0.410^{\mathrm{b}}$ & 1.8 & -0.3 to 3.8 & $0.090^{\mathrm{b}}$ \\
\hline Dorsiflexion & 0.5 & -2.4 to 3.4 & 0.748 & 0.5 & -2.0 to 3.0 & 0.643 \\
\hline \multicolumn{7}{|l|}{ Foot posture (degrees) } \\
\hline Talus-second metatarsal angle & -0.2 & -1.8 to 1.5 & $0.441^{b}$ & 1.3 & -0.1 to 2.6 & 0.063 \\
\hline Talo-navicular angle & -1.4 & -3.1 to 0.3 & $0.095^{\mathrm{b}}$ & 1.0 & -1.0 to 3.0 & 0.284 \\
\hline Calcaneal inclination angle & 0.1 & -0.3 to 0.6 & $0.623^{b}$ & 0.1 & -0.7 to 0.9 & $0.665^{\mathrm{b}}$ \\
\hline Calcaneal-first metatarsal angle & -0.4 & -0.3 to 1.0 & 0.300 & -0.4 & -1.9 to 1.0 & 0.539 \\
\hline
\end{tabular}

$\mathrm{m}$ metres, $\mathrm{kg}$ kilograms, $\mathrm{m}^{2}$ metres squared, $\mathrm{cm}^{2}$ centimetres squared, MOXFQ Manchester-Oxford Foot Questionnaire, $\mathrm{kPa}$ kilopascal, $R O M$ range of motion, $C E S-D$ Center for Epidemiological Studies-Depression scale

${ }^{a} p$ calculated for differences between baseline and follow-up measures analysed with the paired samples t-test unless otherwise stated

${ }^{\mathrm{b}} p$ calculated for differences between baseline and follow-up measures analysed with the Wilcoxon signed-rank test

weight. The reduction of force in the midfoot in our study may have resulted in a larger reduction in peak pressure, if it were not for the significant simultaneous reduction in contact area of the midfoot. Furthermore, a study investigating contact area and body composition found a positive association between total body fat mass, but not fat-free mass, and the midfoot contact area only [43]. Together, these findings suggest that people with higher fat mass may deposit fat mass in the midfoot and, following bariatric surgery, there may be a loss of this fat mass that could appear to elevate the longitudinal arch of the foot. This may have implications for the fit of 


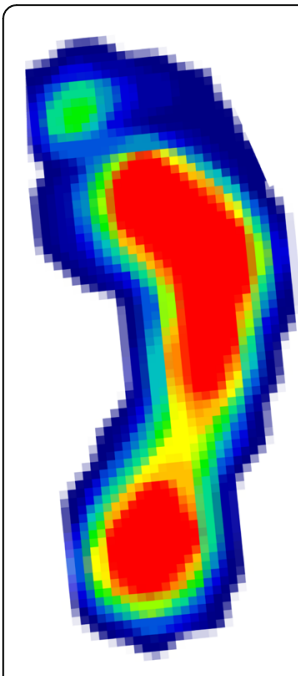

Before bariatric surgery $(135.7 \mathrm{~kg})$

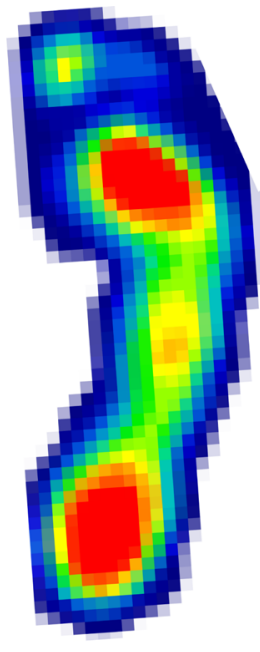

After bariatric surgery $(96.2 \mathrm{~kg})$

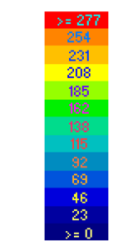
$(\mathrm{kPa})$
Calibrated pressure

Fig. 1 Representative peak plantar pressures during walking before and 6-months following bariatric surgery

footwear or orthoses following soft tissue adaptations after bariatric surgery, and in patients with significant weight loss.

The association between foot pain severity and depressive symptoms has previously been established in a community cohort [44], suggesting that foot pain may be a manifestation of either widespread or reduced threshold for pain that extends beyond localised discomfort. The results of our study are concordant with this premise, although ours are unique given they are exclusively from a bariatric cohort and we were able to adjust for local foot measures, including foot posture and plantar pressure at baseline and follow-up. Given the high prevalence of depression in bariatric surgery candidates, and the improvement in depressive symptoms following surgery [45], it is possible that foot pain severity is mediated by depressive symptoms, rather than by body weight alone. There is evidence that while depressive symptoms improve in the short-term following bariatric surgery, there

Table 5 Repeated measures analysis of change in MOXFQ-index and plantar pressure

\begin{tabular}{lll}
\hline Variable & $\beta$-coefficients $(95 \% \mathrm{Cl})$ & $p$ value \\
\hline Age & $0.5(-0.1$ to 1.2$)$ & 0.123 \\
Gender & $12.0(-1.3$ to 25.4$)$ & 0.077 \\
Peak pressure $^{\mathrm{a}}$ & $0.0(-0.1$ to 0.1$)$ & 0.615 \\
Ankle joint dorsiflexion & $0.3(-0.7$ to 1.3$)$ & 0.541 \\
Contact time & $18.4(-17.9$ to 54.7$)$ & 0.320 \\
Group (treatment) & $-11.2(-23.8$ to 1.4$)$ & 0.081 \\
Time (6-months) & $-7.7(-18.5$ to 3.2$)$ & 0.168 \\
Group*time (6-months) & $-27.1(-40.8$ to -13.5$)$ & $<0.001$ \\
\hline
\end{tabular}

${ }^{\mathrm{a} W h o l e ~ f o o t ~ p e a k ~ p r e s s u r e ~}$ may be attenuation of this improvement in the longer term, and indeed some people have increased depressive symptoms following surgery, often with concomitant weight regain [46]. Whether this causes an exacerbation of musculoskeletal pain is not known, but this may be worth exploring.

This study should be considered in light of some limitations. Firstly, the small sample size limited the number of variables we could include in our models and may have may resulted in type II errors for the variables we did include. Secondly, the cohort was recruited via convenience sampling and consisted of mainly women which may limit the generalisability (and the ability to analyse between gender comparisons) of the findings, however, this is consistent with the demographics that present for bariatric surgery thus findings are applicable to that context [47]. Thirdly, the spatial resolution of the MatScan ${ }^{\circ}$ plantar pressure system is relatively low and thus the sensitivity to detect all changes in plantar pressure may have been compromised. Furthermore, the importance of the size of the sensors used in plantar pressure systems has also been well described [48], and this may have impacted on measuring contact area, particularly for the lesser toe region, which is prone to measurement error [49]. Whilst there are limitations regarding sensor size and spatial resolution, the detection of subtle changes in plantar pressure was less important given the gross changes in body mass (and pressure) that occurs following bariatric surgery. Fourthly, the duration of foot pain was not recorded, so there may be variation of pain duration prior to participant enrolment. Finally, the change in foot pain and plantar pressure was measured over a six-months, and may not reflect changes seen over longer periods.

Nonetheless, this study has a number of strengths. It is the first to examine foot pain, foot posture and plantar pressures in bariatric candidates, reporting the effect of bariatric surgery on all variables. This study also considered relationships between mechanical and non-mechanical factors and foot pain severity at baseline and prospectively following bariatric surgery.

The results of this study provide proof of concept that weight loss improves foot pain, and future studies in this area, including non-surgical weight loss strategies and less obese cohorts, may be warranted. Deeper analysis of gait characteristics before and following weight loss in people with foot pain, may also determine if changes occurring beyond peak plantar pressures are important to consider in this cohort, and even footwear choices may be relevant.

\section{Conclusion}

Foot pain significantly improves following bariatric surgery instigated weight loss, but occurs without a change 
in foot structure. Dynamic peak plantar pressures reduce following bariatric surgery and weight loss, but these changes are not related to changes in pain. Depressive symptoms, however, are significantly related to foot pain both before and following bariatric surgery and associated weight loss. Thus, foot pain in bariatric candidates may be mediated by non-mechanical or non-local factors before and following surgery and resulting weight loss.

\begin{abstract}
Abbreviations
AUS: Australia; BMI: body mass index; CES-D: Center for Epidemiologic Studies Depression; Cl: confidence interval; $\mathrm{cm}$ : centimetre; HREC: Human Research Ethics Committee; Hz: Hertz; IBM: International Business Machines Corporation; ICC: Intraclass correlation coefficient; kg: kilogram: kPa: kilopascal; m: metre; MOXFQ: Manchester-Oxford Foot Questionnaire; ms: millisecond; NY: New York; SD: standard deviation; SPSS: Statistical Package for the Social Sciences; TX: Texas; USA: United States of America
\end{abstract}

\section{Acknowledgments}

TPW is currently supported by a Nursing and Allied Health Scholarship and Support Scheme funded by the Commonwealth Department of Health and administered by Services for Australian Rural and Remote Allied Health. JBA is currently supported by a National Health and Medical Research Council Early Career Research Fellowship (ID: 1120560).

We would like thank Repat Radiology for their generous support with this project. We would also like to thank all of the study participants who made this study possible.

\section{Funding}

This study was funded by a Project Grant from Arthritis Australia.

\section{Availability of data and materials}

The data that support the findings of this study are available from the corresponding author upon reasonable request.

\section{Authors' contributions}

TPW, AME, AY, JBA, JAC, LK and EMS conceived the study and its design. Data collection was performed by TPW and AME. Data analysis was performed by TPW and TKG. All authors provided input into the draft and agreed on the final manuscript. All authors read and approved the final manuscript.

\section{Ethics approval and consent to participate}

The study was approved by the Southern Adelaide Clinical Human Research Ethics Committee, project number 211.14. All participants provided informed consent.

\section{Consent for publication}

Not applicable.

\section{Competing interests}

The authors declare that they have no competing interests.

\section{Publisher's Note}

Springer Nature remains neutral with regard to jurisdictional claims in published maps and institutional affiliations.

\footnotetext{
Author details

${ }^{1}$ College of Medicine and Public Health, Flinders University, Bedford Park, South Australia 5042, Australia. ${ }^{2}$ Department of Orthopaedics and Trauma, The Queen Elizabeth Hospital, Woodville South, South Australia 5011, Australia. ${ }^{3}$ Adelaide Medical School, Faculty of Health and Medical Sciences, The University of Adelaide, Adelaide, South Australia 5005, Australia. ${ }^{4}$ Discipline of Podiatry, College of Science, Health and Engineering, La Trobe University, Bundoora, VIC 3086, Australia. ${ }^{5}$ Nutrition \& Dietetics, College of Nursing and Health Sciences, Flinders University, Bedford Park, South Australia 5042, Australia. ${ }^{6}$ Department of Gastrointestinal Surgery, Flinders Medical Centre, Bedford Park, South Australia 5042, Australia. ${ }^{7}$ Alliance for
}

Research in Exercise, Nutrition and Activity, Sansom Institute for Health Research, School of Health Sciences, University of South Australia, Adelaide, South Australia 5000, Australia. ${ }^{8}$ Department of Rheumatology, Southern Adelaide Local Health Network, Bedford Park, South Australia 5042, Australia.

Received: 8 May 2018 Accepted: 14 June 2018

Published online: 28 June 2018

\section{References}

1. Thomas MJ, Roddy E, Zhang W, Menz HB, Hannan MT, Peat GM. The population prevalence of foot and ankle pain in middle and old age: a systematic review. Pain. 2011;152:2870-80

2. Gill TK, Menz HB, Landorf KB, Arnold JB, Taylor AW, Hill CL. Predictors of foot pain in the community: the north West Adelaide health study. J Foot Ankle Res. 2016;9:23.

3. Butterworth PA, Landorf KB, Smith SE, Menz HB. The association between body mass index and musculoskeletal foot disorders: a systematic review. Obes Rev. 2012:13:630-42

4. Mickle KJ, Steele JR. Obese older adults suffer foot pain and foot-related functional limitation. Gait Posture. 2015:42:442-7.

5. Butterworth PA, Urquhart DM, Landorf KB, Wluka AE, Cicuttini FM, Menz HB. Foot posture, range of motion and plantar pressure characteristics in obese and non-obese individuals. Gait Posture. 2015;41:465-9.

6. Birtane $\mathrm{M}$, Tuna $\mathrm{H}$. The evaluation of plantar pressure distribution in obese and non-obese adults. Clin Biomech (Bristol, Avon). 2004;19:1055-9.

7. Fabris SM, Valezi AC, de Souza SA, Faintuch J, Cecconello I, Junior MP. Computerized baropodometry in obese patients. Obesity Surg. 2006;16:1574-8.

8. van Leeuwen KD, Rogers J, Winzenberg T, van Middelkoop M. Higher body mass index is associated with plantar fasciopathy/"plantar fasciitis": systematic review and meta-analysis of various clinical and imaging risk factors. Br J Sports Med. 2016;50:972-81.

9. Irving DB, Cook JL, Young MA, Menz HB. Obesity and pronated foot type may increase the risk of chronic plantar heel pain: a matched case-control study. BMC Musculoskelet Disord. 2007;8:41

10. Sullivan J, Burns J, Adams R, Pappas E, Crosbie J. Plantar heel pain and foot loading during normal walking. Gait Posture. 2015;41:688-93.

11. Cameron AJ, Magliano DJ, Dunstan DW, Zimmet PZ, Hesketh K, Peeters A, et al. A bi-directional relationship between obesity and health-related quality of life: evidence from the longitudinal AusDiab study. Int J Obes. 2012;36:295-303.

12. Kroenke K, Wu J, Bair MJ, Krebs EE, Damush TM, Tu W. Reciprocal relationship between pain and depression: a 12-month longitudinal analysis in primary care. J Pain. 2011;12:964-73.

13. Luppino FS, de Wit LM, Bouvy PF, Stijnen T, Cuijpers P, Penninx BWJH, et al. Overweight, obesity, and depression: a systematic review and meta-analysis of longitudinal studies. Arch Gen Psychiatry. 2010;67:220-9.

14. Jiang $L$, Xie $X$, Wang $Y$, Wang $Y$, Wang $Y$, Lu Y, et al. Body mass index and hand osteoarthritis susceptibility: an updated meta-analysis. Int J Rheum Dis. 2016;19:1244-54.

15. Cancello R, Clement K. Is obesity an inflammatory illness? Role of low-grade inflammation and macrophage infiltration in human white adipose tissue. BJOG. 2006:113:1141-7.

16. Viester L, Verhagen EA, Oude Hengel KM, Koppes LL, van der Beek AJ, Bongers PM. The relation between body mass index and musculoskeletal symptoms in the working population. BMC Musculoskelet Disord. 2013;14:238.

17. Speck RM, Bond DS, Sarwer DB, Farrar JT. A systematic review of musculoskeletal pain among bariatric surgery patients: implications for physical activity and exercise. Surg Obes Relat Dis. 2014;10:161-70.

18. McGoey BV, Deitel M, Saplys R, Kliman ME. Effect of weight loss on musculoskeletal pain in the morbidly obese. J Bone Joint Surg Br. 1990;72:322-3.

19. Hooper MM, Stellato TA, Hallowell PT, Seitz BA, Moskowitz RW. Musculoskeletal findings in obese subjects before and after weight loss following bariatric surgery. Int J Obes. 2007;31:114-20.

20. Gill SV, Walsh MK, Pratt JA, Toosizadeh N, Najafi B, Travison TG. Changes in spatiotemporal gait patterns during flat ground walking and obstacle crossing 1 year after bariatric surgery. Surg Obes Relat Dis. 2016;12:1080-5

21. Ng M, Fleming T, Robinson M, Thomson B, Graetz N, Margono C, et al. Global, regional, and national prevalence of overweight and obesity in children and adults during 1980-2013: a systematic analysis for the global burden of disease study 2013. Lancet. 2014;384:766-81. 
22. Collins SL, Moore RA, McQuay HJ. The visual analogue pain intensity scale: what is moderate pain in millimetres? Pain. 1997;72:95-7.

23. Nuttall FQ. Body mass index: obesity, BMI, and health. A Critical Review Nutr Today. 2015;50:117-28

24. Morley D, Jenkinson C, Doll H, Lavis G, Sharp R, Cooke P, et al. The Manchester-Oxford foot questionnaire (MOXFO): development and validation of a summary index score. Bone Joint Res. 2013;2:66-9.

25. Radloff LS. The CES-D scale a self-report depression scale for research in the general population. Appl Psychol Meas. 1977;1:385-401.

26. Giacomozzi C. Appropriateness of plantar pressure measurement devices: a comparative technical assessment. Gait Posture. 2010;32:141-4.

27. Zammit GV, Menz HB, Munteanu SE. Reliability of the TekScan MatScan(R) system for the measurement of plantar forces and pressures during barefoot level walking in healthy adults. J Foot Ankle Res. 2010;3:11.

28. Bryant A, Singer K, Tinley P. Comparison of the reliability of plantar pressure measurements using the two-step and midgait methods of data collection. Foot Ankle Int. 1999;20:646-50.

29. Menz H. Two feet, or one person? Problems associated with statistical analysis of paired data in foot and ankle medicine. Foot (Edinb). 2004;14:2-5.

30. Keijsers NL, Stolwijk NM, Pataky TC. Linear dependence of peak, mean, and pressure-time integral values in plantar pressure images. Gait Posture. 2010;31:140-2.

31. Waaijman R, Bus SA. The interdependency of peak pressure and pressuretime integral in pressure studies on diabetic footwear: no need to report both parameters. Gait Posture. 2012;35:1-5.

32. Taylor AJ, Menz HB, Keenan A-M. The influence of walking speed on plantar pressure measurements using the two-step gait initiation protocol. Foot (Edinb). 2004;14:49-55

33. Murley GS, Menz HB, Landorf KB. A protocol for classifying normal- and flatarched foot posture for research studies using clinical and radiographic measurements. J Foot Ankle Res. 2009:2:22.

34. Munteanu SE, Strawhorn AB, Landorf KB, Bird AR, Murley GS. A weightbearing technique for the measurement of ankle joint dorsiflexion with the knee extended is reliable. J Sci Med Sport. 2009;12:54-9.

35. Menadue C, Raymond J, Kilbreath SL, Refshauge KM, Adams R. Reliability of two goniometric methods of measuring active inversion and eversion range of motion at the ankle. BMC Musculoskelet Disord. 2006;7:60

36. Lavery LA, Armstrong DG, Boulton AJ. Diabetex research group. Ankle Equinus deformity and its relationship to high plantar pressure in a large population with diabetes mellitus. J Am Podiatr Med Assoc. 2002:92:479-82

37. Burnfield JM, Few CD, Mohamed OS, Perry J. The influence of walking speed and footwear on plantar pressures in older adults. Clin Biomech (Bristol, Avon). 2004;19:78-84

38. Wandner LD, Scipio CD, Hirsh AT, Torres CA, Robinson ME. The perception of pain in others: how gender, race, and age influence pain expectations. Pain. 2012;13:220-7.

39. Arnold JB, Causby R, Jones $\mathrm{S}$. The impact of increasing body mass on peak and mean plantar pressure in asymptomatic adult subjects during walking. Diabet Foot Ankle. 2010;1. https://www.ncbi.nlm.nih.gov/pubmed/22396809.

40. Song J, Kane R, Tango DN, Veur SS, Furmato J, Komaroff E, et al. Effects of weight loss on foot structure and function in obese adults: a pilot randomized controlled trial. Gait Posture. 2015;41:86-92.

41. Price C, Nester C. Foot dimensions and morphology in healthy weight, overweight and obese males. Clin Biomech (Bristol, Avon). 2016;37: $125-30$

42. Walsh TP, Butterworth PA, Urquhart DM, Cicuttini FM, Landorf KB, Wluka AE, et al. Increase in body weight over a two-year period is associated with an increase in midfoot pressure and foot pain. J Foot Ankle Res. 2017;10:31.

43. Wearing SC, Hills AP, Byrne NM. The arch index: a measure of flat or fat feet? Foot Ankle Int. 2004;25:575-81.

44. Awale A, Dufour AB, Katz P, Menz HB, Hannan MT. Link between foot pain severity and prevalence of depressive symptoms. Arthritis Care Res (Hoboken). 2016;68:871-6.

45. Dixon JB, Dixon ME, O'Brien PE. Depression in association with severe obesity: changes with weight loss. Arch Intern Med. 2003;163:2058-65.

46. Switzer NJ, Debru E, Church N, Mitchell P, Gill R. The impact of bariatric surgery on depression: a review. Curr Cardiovasc Risk Rep. 2016;10:12.
47. Australian Institute of Health and Welfare. Weight loss surgery in Australia 2014-15: Australian hospital Statistics Cat. no. HSE 186. Canberra: AlHW; 2017

48. Urry S. Plantar pressure-measurement sensors. Meas Sci Technol. 1999;10:R16-32

49. Urry SR, Wearing SC. The accuracy of footprint contact area measurements: relevance to the design and performance of pressure platforms. Foot (Edinb). 2001;11:151-7.

\section{Ready to submit your research? Choose BMC and benefit from:}

- fast, convenient online submission

- thorough peer review by experienced researchers in your field

- rapid publication on acceptance

- support for research data, including large and complex data types

- gold Open Access which fosters wider collaboration and increased citations

- maximum visibility for your research: over $100 \mathrm{M}$ website views per year

At BMC, research is always in progress.

Learn more biomedcentral.com/submissions 